\title{
Investigating radio-frequency identification usage behaviours and organisational performance according to factors of user perception
}

\section{Ling-Lang Tang, Ya-wen Chan* and Sheng-Lun Shen}

College of Management,

Yuan Ze University,

135 Yuan-Tung Road,

Chung-Li, 32003, Taiwan

Email: balltang@saturn.yzu.edu.tw

Email: cyw812@gmail.com

Email: shenglun@saturn.yzu.edu.tw

*Corresponding author

\begin{abstract}
Information technology has developed rapidly in the past decades, in particular the use of service-oriented architectures, which have been widely adopted in Taiwan's healthcare industry. Radio-frequency identification (RFID) is one of the most widely applied new technologies. Using the unified theory of acceptance and use of technology model, this study investigated the effect of perceived security (PS) and privacy concerns (PC) on health professionals' RFID usage behaviour (UB), and the effect of UB on organisational performance (OP). A questionnaire survey was used and 410 valid questionnaires were returned. The results of path analysis revealed that performance expectancy (PE), effort expectancy (EE), social influence, and facilitating conditions (FC) exert a significantly positive influence on UB; PS has a significantly positive effect on PE and PC; and UB exerts a significantly positive influence on OP. Different demographic variables also moderated the effect of PE, EE, and FC on RFID UB.
\end{abstract}

Keywords: healthcare; unified theory of acceptance and use of technology; UTUT; radio-frequency identification; RFID; service-oriented architecture.

Reference to this paper should be made as follows: Tang, L-L., Chan, Y-w. and Shen, S-L. (2019) 'Investigating radio-frequency identification usage behaviours and organisational performance according to factors of user perception', Int. J. Services Technology and Management, Vol. 25, Nos. 3/4, pp.199-214.

Biographical notes: Ling-Lang Tang is an Associate Professor in the School of Management at Yuan Ze University of Taiwan. His research interests are in the areas of quality management, supply chain management, and e-business etc.

Ya-wen Chan is currently a $\mathrm{PhD}$ student of Management Electronics and Service Science at Yuan Ze University and is also a Leader of International Affairs at Fo Guang University. Her research interests include service innovation, health care management, and project management. 
Sheng-Lun Shen is a PhD and Adjunct Lecturer in the College of Management, Yuan Ze University. His research interests include technology management and health care management.

\section{Introduction}

Radio-frequency identification (RFID) significantly enhances patient safety, operational efficiency, and service quality within the healthcare industry. To elucidate the operating procedures of new medical technologies, RFID, wireless technology, Internet operating procedures, and intelligent agents are integrated within a service-oriented architecture (SOA) to initiate new business process automation. One study conducted in the United States indicated that the application of RFID in medical technology has received considerable social support and trust (Katz and Rice, 2009). In a healthcare context, RFID is commonly used in medical apparatus tracking, first aid assignment, patient positioning systems, operation management, neonatal management, long-term care, medical record management, medical waste control, pharmaceutical dispensing, and electronic medical records management. In addition, RFID increases the operating efficiency of data writing and reading, accelerates information exchange and sharing, and effectively reduces human errors in medical practices, thereby enhancing the practices' overall safety level.

When a company or healthcare institution introduces a new technology, a set of methods is required to evaluate its effectiveness. In Taiwan's healthcare industry, RFID is employed on a considerable scale, with related systems having been established in an effort to utilise the technology as effectively as possible. RFID has also been integrated into several related medical technologies and is ranked highly among those receiving the strongest support during technology promotion (Lu et al., 2013). The unified theory of acceptance and use of technology (UTAUT) is highly appropriate for determining and verifying the effectiveness of new technologies (Kijsanayotin et al., 2009). Maillet et al. (2015) used the UTUAT to investigate the levels of recognition and satisfaction in the end-users of electronic patient record systems, in addition to nurses' acceptance of medical technologies that utilise RFID and the functionality of actual applications. In addition to RFID or electronic patient record systems, numerous other digital technologies have been widely applied in healthcare systems. Nuq and Aubert (2013) specified that when promoting digitisation, the healthcare industry must adopt multiple quantification methods to measure the level of acceptance of new technologies by healthcare professionals and must identify actual situations in which such technologies are applied; among all the related methods, the UTUAT model was concluded to be a highly appropriate model for such an investigation.

Technology advances rapidly and multiple new technologies have been introduced to various industries, including SOAs. Because new technology is used in healthcare to coordinate or optimise organisational performance (OP), patient safety, and patient services, medical institutions tend to be extremely prudent when introducing new 
technology. Careful assessment must be performed to determine the effectiveness of such technologies, in particular how their application benefits patients and healthcare professionals. This study adopted the UTUAT to investigate the effect of RFID introduction on several healthcare institutions in Taiwan. The results may serve as a reference for other healthcare institutions seeking to implement RFID technology.

\section{Literature review}

\subsection{Application of RFID in Taiwan's healthcare industry}

Lai et al. (2014) concluded that using appropriate information technology can significantly improve hospital operations and services and that RFID is an innovative technology for collecting data and tracking personnel and assets. Because RFID offers multiple conveniences for healthcare institution operations and services, numerous healthcare institutions have adopted this technology to facilitate delivering healthcare services. To optimise medical procedures, enhance healthcare service quality, and improve patient safety management, hospitals can use RFID for integrated and automated patient tracking.

In Taiwan's healthcare industry, RFID has been used to prevent treatment errors, identify adverse events, and improve patient safety, and has also been applied in postnatal care. Women who have used the RFID postnatal care system have claimed that is reliable and secure, ensures their personal safety, and offers various types of patient care (Wang et al., 2015). In addition to postnatal care applications, RFID is also used to integrate healthcare information systems with medication systems, which helps healthcare professionals to identify inpatients and thus reduces prescription error frequency (which was formerly operated according to the principle of three readings and five confirmations suggested by Taiwan's Ministry of Health and Welfare), thereby enhancing medication safety.

Hospital accreditation and evaluation periods are crucial to Taiwanese healthcare institutions. Nosocomial infections are a key indicator during evaluation of patient safety and hospital performance. RFID can be used to monitor and track the clinical exposure history of nurses and patients, thus effectively enabling control of nosocomial infections in intensive care units, accurate estimation of intensive care unit activity, and other applications to be used in different ward types (Chang et al., 2011).

RFID can be applied to a wide range of practices in the healthcare industry, covering the management of personnel, assets, scheduling, and locations, including: identification of patients and nurses; monitoring and tracking of patients; management of patients' exposure history; usage frequency of expensive medical apparatuses, medicines, and equipment; and waste control. These functions together constitute an SOA. One previous study investigated the implementation of RFID in a high-efficiency particulate air ventilation system in the operating rooms of a medical centre in Taiwan. By adopting RFID detectors and a reaction system, the ventilation system could determine which health professionals were present in an operating room and execute related controls. Related research determined that applying RFID enhances the efficiency of ventilation systems and reduces energy consumption (Lin et al., 2012). 


\subsection{Applications of the UTUAT in the healthcare industry}

Venkatesh et al. (2003) formulated the UTAUT on the basis of the theory of reasoned action (Fishbein and Ajzen, 1975) and further modified it on the basis of a revised version of the technology acceptance model (Venkatesh and Davis, 1996). In the UTAUT model, performance expectancy (PE), effort expectancy (EE), social influence (SI), and facilitating conditions (FC) constitute the four main dimensions and sex, age, experience, and voluntariness serve as the moderators. The purpose of this model is to enable investigation of the influence of behavioural intentions on usage behaviour (UB).

The UTAUT has been applied in the healthcare industry to assess the possible effectiveness of a new technology to be introduced. According to Heselmans et al. (2012), whether an electronic decision support system can be successfully implemented in the healthcare industry can be determined by employing the UTUAT as a quantified assessment method. The UTUAT can also be used to evaluate the effectiveness of a new technology that has already been introduced. Duyck et al. (2010) maintained that to successfully introduce a technology in healthcare facilities, numerous other obstacles must be overcome in addition to funding and technological issues. The UTAUT is a highly appropriate tool for evaluating the success of technology implementation. Therefore, the UTUAT is suitable for performing assessments before and after a new technology has been introduced.

In addition to assessing the effectiveness of a new technology, the UTAUT can be applied to assess health professionals' UB regarding specific technologies. Han et al. (2006) used the technology acceptance model (Venkatesh and Davis, 1996) and UTUAT (Venkatesh et al., 2003) to investigate physicians' usage of mobile communications technology for healthcare purposes, in which perceived usefulness, interaction effects, and compatibility were identified as the determinants. However, several studies have indicated that several dimensions of the UTUAT may be unsuitable for assessing health professionals. In contrast to the results of other studies that have adopted the UTUAT, Jeng and Tzeng (2012) discovered that SI does not affect the behavioural intentions of health professionals.

In a UTUAT derivative study, Alaiad and Zhou (2014) adopted privacy concerns (PC), trust, ethical issues, and legal issues as four new dimensions in the UTUAT to investigate the difference between technological development and the clinical application of homecare robots. The results revealed that PC, trust, and ethical issues significantly affected the intention to use homecare robots. Hsu et al. (2013) used the UTUAT as a basis for investigating the problems and challenges of privacy protection in healthcare information systems. PS and information security literacy were added to the model in that study to determine their influence on adoption intentions, with PS discovered to significantly affect adoption intentions.

\subsection{Healthcare security and privacy}

Multiple electronic applications have been developed for use in the field of healthcare; among them, systems for managing personal health records provide an information environment in which personal healthcare information can be managed and shared using electronic files. Such systems assist physicians in assessing their patients' situations according to their personal healthcare history. However, electronic healthcare information systems such as personal health records should place emphasis on the 
security of the overall healthcare system and database if they are to be applicable in healthcare institutions. The quality of healthcare services is a key factor affecting healthcare satisfaction and behavioural intentions, and it comprises manipulatable items such as security, trust, and ethical behaviour. These items are also relevant when evaluating the quality of digitised healthcare services and can serve as diagnosis tools for patients when evaluating healthcare service quality (Hadwich et al., 2010).

For public-health-related issues, numerous cutting-edge mobile healthcare systems have been implemented to facilitate disease treatment and containment. Although mobile healthcare systems possess excellent feedback and communication capabilities during data collection, they must adhere to standardised data encryption standards under an open framework to ensure data security, patient privacy, and data transmission (Tate et al., 2013). An increasing number of public and private institutes have developed healthcare software that can facilitate information exchange among healthcare institutions. Standardisation ensures that the procedures of various service providers are consistent, thereby minimising costs and maximising economic benefit. However, problems regarding information security have led to disputes over such systems (Johnson, 2011).

Anderson and Agarwal (2011) reported that privacy and the protection of personal healthcare information in digitised healthcare systems have received the most public attention. Anderson and Agarwal (2011) also indicated that personal healthcare information can be released for healthcare, research, and marketing purposes only at the request of patient health stakeholders such as hospitals, physicians, governments, and pharmaceutical manufacturers. In fact, individual willingness to provide healthcare information depends on trust, information sensitivity, and PC. Differences in individual willingness are determined by internal factors such as individual personality, personality traits, information sensitivity, health status, and acknowledgement of risk (Bansal et al., 2010).

Several wireless wearable network devices have been developed and applied in the field of electronic healthcare. For example, wireless body area networks can be realised by implanting small electronic devices into the human body to collect various information through sensors. Although such devices have been developed to collect personal information, strict control measures must be implemented to protect patient safety and privacy ( $\mathrm{Li}$ et al., 2010). RFID has been widely used in healthcare and other services, and numerous managers are considering using RFID to enhance business performance. Of the multiple challenges that RFID systems face, including improper supply chain planning and a lack of technology convergence, customer privacy remains the greatest concern. Therefore, handling customer privacy satisfactorily can improve the sharing of real-time information (Kumar et al., 2011).

\section{Research methods}

\subsection{Research framework}

In recent years, RFID has been widely applied to various operations and services in Taiwan's healthcare industry. When information technology develops rapidly, tools must be implemented to evaluate their effectiveness, the results of which can provide a reference for managers and future users of RFID systems. However, security and privacy 
issues regarding such new technology in the health sector have received considerable attention, even to the extent of affecting health professionals' UB (Alaiad and Zhou, 2014; Hsu et al., 2013). Consequently, the present study modified the UTUAT by adding two dimensions, PS and PC, to investigate health professionals' intentions to use RFID systems. Health professionals' usage intentions can affect the OP of an entire healthcare institution (Minvielle et al., 2005; Tsai and Wu, 2010). Therefore, this study investigated whether health professionals' intention to use RFID systems affects their OP.

Figure 1 illustrates the research framework of this study, showing that it was mainly focused on the four dimensions of the UTUAT: PE, EE, SI, and FC. Because of the results of previous studies, PS and PC were added as two new dimensions. Sex, age, and experience served as moderators of health professionals' intention to use an RFID system. Finally, the influence of use intention on OP was investigated. This study assessed hospital-based health professionals who had previously used RFID systems or had been involved in RFID-related programs. To ensure that the items in the dimensions were appropriate, the present study referred to previous studies on healthcare-related UTUAT applications and redefined the dimensions and corresponding items accordingly. Table 1 lists the sources and definitions of the dimensions used in the present study.

Figure 1 Research framework

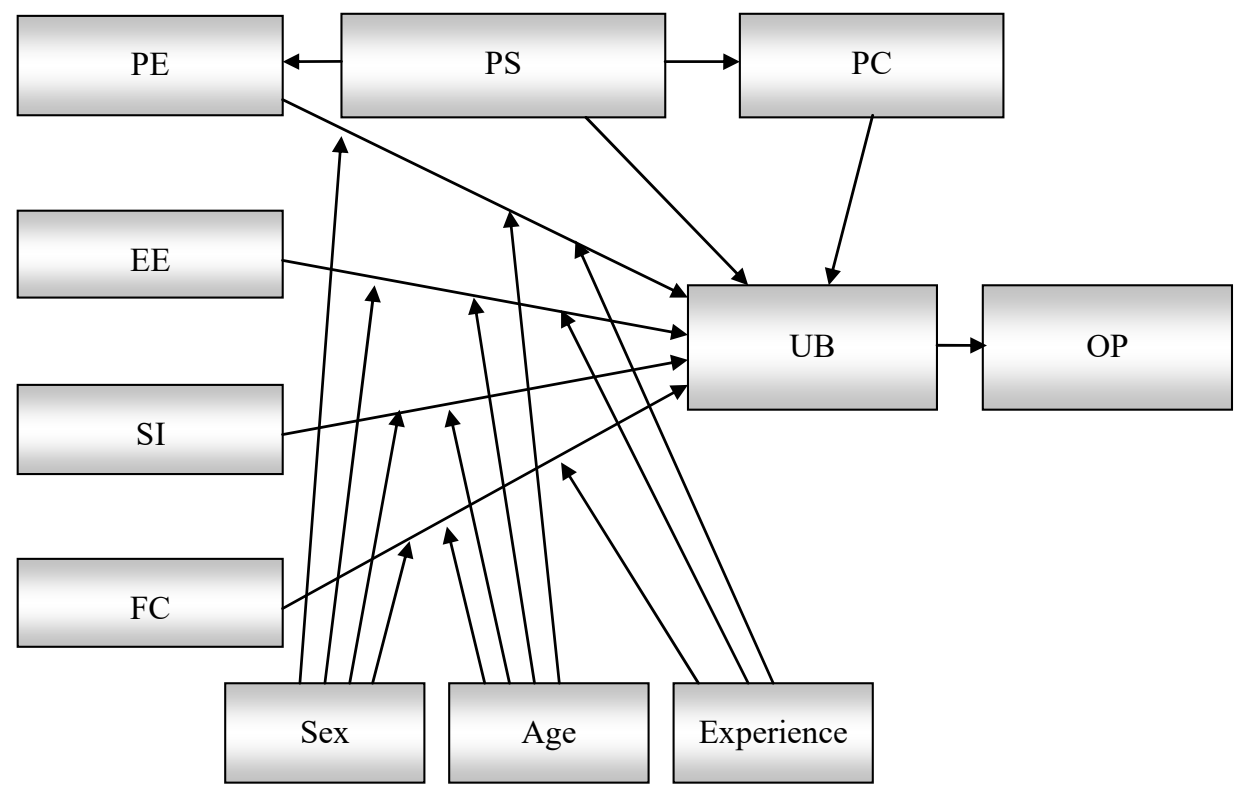

Data in the present study were collected using a questionnaire. The questionnaire items were measured using a seven-point Likert scale. Respondents were healthcare professionals at various healthcare institutions in Taiwan who had experience with RFID technology. The data were subsequently analysed through a Pearson's correlation analysis, factor analysis, and path analysis. AMOS and SPSS were used for the analysis. 
Table 1 Compilation of research dimensions

\begin{tabular}{|c|c|c|}
\hline Dimension & Reference source & Definition of the dimension \\
\hline $\mathrm{PE}$ & $\begin{array}{l}\text { Duyck et al. (2010), } \\
\text { Maillet et al. (2015) and } \\
\text { Venkatesh et al. (2003) }\end{array}$ & $\begin{array}{l}\text { Health professionals' perspectives on RFID, } \\
\text { specifically whether RFID enhances their work } \\
\text { efficiency, enabling them to complete tasks } \\
\text { quickly and improve the quality of healthcare. }\end{array}$ \\
\hline $\mathrm{EE}$ & $\begin{array}{l}\text { Maillet et al. (2015), } \\
\text { Nuq and Aubert (2013) and } \\
\text { Venkatesh et al. (2003) }\end{array}$ & $\begin{array}{l}\text { Health professionals' perspectives on RFID, } \\
\text { particularly whether RFID is a technology that is } \\
\text { easy to learn and whether it is practical for work } \\
\text { tasks. }\end{array}$ \\
\hline SI (SI) & $\begin{array}{l}\text { Heselmans et al. (2012), } \\
\text { Maillet et al. (2015) and } \\
\text { Venkatesh et al. (2003) }\end{array}$ & $\begin{array}{l}\text { Whether health professionals have acknowledged } \\
\text { the importance of RFID to their work environment } \\
\text { and co workers, thereby accepting and adopting } \\
\text { RFID. }\end{array}$ \\
\hline $\mathrm{FC}$ & $\begin{array}{l}\text { Maillet et al. (2015), } \\
\text { Nuq and Aubert (2013) and } \\
\text { Venkatesh et al. (2003) }\end{array}$ & $\begin{array}{l}\text { Whether health professionals' perceptions of } \\
\text { conditions encourage them to use RFID, and } \\
\text { whether the hospital provides adequate support on } \\
\text { how to use RFID systems. }\end{array}$ \\
\hline PS & Hsu et al. (2013) & $\begin{array}{l}\text { The level of trustworthiness that health } \\
\text { professionals have toward RFID, particularly } \\
\text { regarding its security level during usage and the } \\
\text { extent of protection it offers to personal } \\
\text { information. }\end{array}$ \\
\hline $\mathrm{PC}$ & Alaiad and Zhou (2014) & $\begin{array}{l}\text { The level to which health professionals recognise } \\
\text { RFID privacy protection policies, specifically that } \\
\text { RFID will not allow unauthorised access by third } \\
\text { parties to protected data. }\end{array}$ \\
\hline UB & $\begin{array}{l}\text { Alaiad and Zhou (2014) and } \\
\text { Venkatesh et al. (2003) }\end{array}$ & $\begin{array}{l}\text { The emotions and preferences that health } \\
\text { professionals have toward using RFID, particularly } \\
\text { whether they are aware of the benefits and } \\
\text { advantages RFID can bring to the hospital and } \\
\text { their work tasks. }\end{array}$ \\
\hline OP & $\begin{array}{l}\text { Minvielle et al. (2005), } \\
\text { Tsai and } \mathrm{Wu}(2010) \text { and } \\
\text { Zelbst et al. (2012) }\end{array}$ & $\begin{array}{l}\text { Whether health professionals consider that } \\
\text { introducing RFID enhances hospital income, } \\
\text { profits, service quality, and return on investment. }\end{array}$ \\
\hline
\end{tabular}

\section{Empirical analysis}

\subsection{Reliability and validity}

After interviews were conducted with health professionals, 410 valid questionnaires were returned. In the initial model assessment phase, the primary task was to examine the reliability and validity of the research model. The reliability and validity of the items were assessed to ensure the suitability of the dimensions for structural equation modelling. Confirmatory factor analysis was conducted on all the dimensions and items to evaluate the model.

Among the eight dimensions under investigation (PE, EE, SI, FC, PS, PC, UB, and OP), the standardised factor loadings were all $\geq 0.7$ and achieved the level of statistical 
significance; the squared multiple correlation values were all $\geq 0.5$; and the composite reliability (CR) of all dimensions was $>0.5$ (Table 2). Therefore, the model had satisfactory reliability and excellent internal consistency. In addition, the average variance extracted (AVE) of all the dimensions were $>0.5$. According to the analysis results presented in Table 2, the proposed assessment model met the evaluation requirements (i.e., convergent validity: 0.95); therefore, the model exhibits satisfactory convergent validity.

Table 2 Model assessment analysis results

\begin{tabular}{|c|c|c|c|c|c|c|c|c|}
\hline Variable & Item & $\begin{array}{l}\text { Standardised } \\
\text { estimates }\end{array}$ & $\begin{array}{c}\text { Non- } \\
\text { standardised } \\
\text { estimates }\end{array}$ & $S E$ & Sig. & $\begin{array}{c}\text { Squared } \\
\text { multiple } \\
\text { correlation }\end{array}$ & $C R$ & $A V E$ \\
\hline \multirow[t]{5}{*}{$\mathrm{PE}$} & PE1 & 0.895 & 1.000 & & & 0.801 & 0.938 & 0.753 \\
\hline & PE2 & 0.846 & 0.917 & 0.038 & $* * *$ & 0.716 & & \\
\hline & PE3 & 0.904 & 1.027 & 0.036 & $* * *$ & 0.817 & & \\
\hline & PE4 & 0.885 & 0.972 & 0.037 & $* * *$ & 0.783 & & \\
\hline & PE5 & 0.804 & 0.899 & 0.041 & $* * *$ & 0.646 & & \\
\hline \multirow[t]{5}{*}{ EE } & EE1 & 0.772 & 1.000 & & & 0.596 & 0.902 & 0.648 \\
\hline & EE2 & 0.769 & 0.954 & 0.058 & $* * *$ & 0.591 & & \\
\hline & EE3 & 0.842 & 1.019 & 0.055 & $* * *$ & 0.709 & & \\
\hline & EE4 & 0.821 & 0.947 & 0.054 & $* * *$ & 0.674 & & \\
\hline & EE5 & 0.819 & 0.941 & 0.054 & $* * *$ & 0.671 & & \\
\hline \multirow[t]{5}{*}{$\mathrm{PC}$} & $\mathrm{PC} 1$ & 0.871 & 1.000 & & & 0.759 & 0.942 & 0.767 \\
\hline & $\mathrm{PC} 2$ & 0.941 & 1.126 & 0.038 & $* * *$ & 0.885 & & \\
\hline & PC3 & 0.941 & 1.111 & 0.038 & $* * *$ & 0.885 & & \\
\hline & PC4 & 0.864 & 0.989 & 0.041 & $* * *$ & 0.746 & & \\
\hline & PC5 & 0.748 & 0.779 & 0.042 & $* * *$ & 0.560 & & \\
\hline \multirow[t]{5}{*}{ PS } & PS1 & 0.737 & 1.000 & & & 0.543 & 0.908 & 0.665 \\
\hline & PS2 & 0.864 & 1.173 & 0.065 & $* * *$ & 0.746 & & \\
\hline & PS3 & 0.820 & 0.990 & 0.059 & $* * *$ & 0.672 & & \\
\hline & PS4 & 0.811 & 1.010 & 0.061 & $* * *$ & 0.658 & & \\
\hline & PS5 & 0.841 & 1.080 & 0.063 & $* * *$ & 0.707 & & \\
\hline \multirow[t]{4}{*}{ SI } & SI2 & 0.579 & 1.000 & & & 0.335 & 0.841 & 0.576 \\
\hline & SI3 & 0.701 & 1.134 & 0.103 & $* * *$ & 0.491 & & \\
\hline & SI4 & 0.851 & 1.422 & 0.118 & $* * *$ & 0.724 & & \\
\hline & SI5 & 0.867 & 1.454 & 0.121 & $* * *$ & 0.752 & & \\
\hline \multirow[t]{5}{*}{$\mathrm{FC}$} & $\mathrm{FC} 1$ & 0.731 & 1.000 & & & 0.534 & 0.870 & 0.573 \\
\hline & $\mathrm{FC} 2$ & 0.780 & 0.988 & 0.064 & $* * *$ & 0.608 & & \\
\hline & FC3 & 0.796 & 0.987 & 0.063 & $* * *$ & 0.634 & & \\
\hline & FC4 & 0.744 & 0.925 & 0.062 & $* * *$ & 0.554 & & \\
\hline & FC5 & 0.732 & 0.943 & 0.064 & $* * *$ & 0.536 & & \\
\hline
\end{tabular}

Note: ${ }^{*} p<0.05,{ }^{* *} p<0.01, * * * p<0.001$ 
Table 2 Model assessment analysis results (continued)

\begin{tabular}{lcccccccc}
\hline Variable & Item & $\begin{array}{c}\text { Standardised } \\
\text { estimates }\end{array}$ & $\begin{array}{c}\text { Non } \\
\text { standardised } \\
\text { estimates }\end{array}$ & SE & Sig. & $\begin{array}{c}\text { Squared } \\
\text { multiple } \\
\text { correlation }\end{array}$ & CR & AVE \\
\hline OP & OP5 & 0.888 & 1.000 & & & 0.789 & 0.914 & 0.682 \\
& OP4 & 0.815 & 0.999 & 0.045 & $* * *$ & 0.664 & & \\
& OP3 & 0.850 & 0.877 & 0.037 & $* * *$ & 0.723 & & \\
& OP2 & 0.876 & 0.990 & 0.039 & $* * *$ & 0.767 & & \\
& OP1 & 0.684 & 0.748 & 0.046 & $* * *$ & 0.468 & & \\
UB & UB1 & 0.777 & 1.000 & & & 0.604 & 0.918 & 0.691 \\
& UB2 & 0.868 & 1.111 & 0.056 & $* * *$ & 0.753 & & \\
& UB3 & 0.889 & 1.107 & 0.055 & $* * *$ & 0.790 & & \\
& UB4 & 0.848 & 1.086 & 0.057 & $* * *$ & 0.719 & & \\
& UB5 & 0.768 & 1.013 & 0.061 & $* * *$ & 0.590 & & \\
\hline
\end{tabular}

Note: ${ }^{*} p<0.05, * * p<0.01, * * * p<0.001$

This study adopted confidence intervals to analyse the model's discriminant validity. A discriminant analysis was conducted using the bias-corrected percentile method and percentile method in AMOS.

The results in Table 3 show that none of the confidence intervals of the standardised correlation coefficients had a value of 1 , indicating that all the dimensions exhibited discriminant validity. The standardised correlation coefficients between the latent dimensions of the model were in the range of $0.515-0.821$, and all the correlation coefficients were $<0.85$. Thus, no collinearity was found among the dimensions.

Table 3 Estimates of the confidence intervals for discriminant validity

\begin{tabular}{lcccccccc}
\hline & $U B$ & $O P$ & $F C$ & $S I$ & $D S$ & $P C$ & $E E$ & $P E$ \\
\hline UB & 0.691 & & & & & & & \\
OP & 0.776 & 0.682 & & & & & & \\
FC & 0.723 & 0.615 & 0.573 & & & & & \\
SI & 0.426 & 0.406 & 0.729 & 0.576 & & & & \\
DS & 0.537 & 0.531 & 0.558 & 0.383 & 0.665 & & & \\
PC & 0.429 & 0.396 & 0.393 & 0.257 & 0.677 & 0.767 & & \\
EE & 0.590 & 0.476 & 0.591 & 0.456 & 0.288 & 0.118 & 0.648 & \\
PE & 0.513 & 0.440 & 0.434 & 0.303 & 0.235 & 0.102 & 0.738 & 0.753 \\
\hline
\end{tabular}

\subsection{Descriptive statistics}

To understand the respondents' demographic variables and sample distribution, descriptive statistical analysis was performed to obtain the frequencies and percentages within demographical data, specifically sex, age, work experience, affiliated institution, and job title. As shown in Table 4, most of the participants were female (79.3\%) and most were between 20 and 40 years of age (73.2\%). The largest group by work 
experience had one to five years of experience (36.6\%). More than half of the respondents (59.8\%) worked in district hospitals.

Table 4 Respondents' demographic information

\begin{tabular}{|c|c|c|c|}
\hline Item & Option & Frequency & Percentage (\%) \\
\hline \multirow[t]{2}{*}{ Sex } & Male & 85 & 20.7 \\
\hline & Female & 325 & 79.3 \\
\hline \multirow[t]{5}{*}{ Age (years) } & $\leq 19$ & 2 & 0.5 \\
\hline & $20-30$ & 164 & 40 \\
\hline & $31-40$ & 136 & 33.2 \\
\hline & $41-50$ & 85 & 20.7 \\
\hline & $\geq 51$ & 23 & 5.6 \\
\hline \multirow{5}{*}{$\begin{array}{l}\text { Work experience } \\
\text { (years) }\end{array}$} & $<1$ & 44 & 10.7 \\
\hline & $1-5$ & 150 & 36.6 \\
\hline & $6-10$ & 92 & 22.4 \\
\hline & $11-15$ & 65 & 15.9 \\
\hline & $>15$ & 59 & 14.4 \\
\hline \multirow[t]{3}{*}{ Affiliated institution } & Medical centre & 31 & 7.6 \\
\hline & District hospital & 245 & 59.8 \\
\hline & Regional hospital & 134 & 32.7 \\
\hline \multirow[t]{4}{*}{ Job title } & Physician & 35 & 8.5 \\
\hline & Nursing personnel & 201 & 49 \\
\hline & $\begin{array}{l}\text { Administrative personnel } \\
\text { and executive }\end{array}$ & 96 & 23.4 \\
\hline & $\begin{array}{l}\text { Other (e.g., physiotherapist, } \\
\text { dietician, pharmacist, and } \\
\text { physical counsellor) }\end{array}$ & 78 & 19 \\
\hline
\end{tabular}

\subsection{Path analysis}

During the model's assessment, confirmatory factor analysis was conducted to determine the reliability, validity, and goodness-of-fit indices to establish a structural model. A path analysis was subsequently performed to identify correlations among all variables. In the structural analysis of the model dimensions, PE, EE, SI, FC, and PS were first examined in a path analysis to $\mathrm{PC}$ and UB. Table 5 presents the results.

$\mathrm{PE}$ (path coefficient $=0.199, p<0.01)$, EE $(0.178, p<0.05)$, SI $(-0.210, p<0.01)$, FC $(0.567, p<0.001)$, and PC $(0.213, p<0.001)$ had a significantly positive effect on UB. However, the effect of PS on UB was insignificant (path coefficient $=0.092$, $p>0.05$ ). In addition, UB had a significantly positive effect on OP (path coefficient $=0.896, p<0.001)$, PS had a significantly positive effect on PE $(0.507, p<0.001)$, and PS had a significantly positive effect on PC $(0.816, p<0.001)$. Figure 2 illustrates the path analysis results. 
Table 5 Path analysis results

\begin{tabular}{|c|c|c|c|c|c|c|c|}
\hline Path & & & $\begin{array}{c}\text { Standardised } \\
\text { path } \\
\text { coefficient }\end{array}$ & $\begin{array}{c}\text { Non } \\
\text { standardised } \\
\text { path coefficient }\end{array}$ & $S E$ & $t$ value & Sig. \\
\hline $\mathrm{PE}$ & $\rightarrow$ & UB & 0.199 & 0.181 & 0.061 & 2.991 & $* *$ \\
\hline EE & $\rightarrow$ & UB & 0.178 & 0.177 & 0.085 & 2.09 & $*$ \\
\hline SI & $\rightarrow$ & UB & -0.210 & -0.267 & 0.099 & -2.693 & $* *$ \\
\hline $\mathrm{FC}$ & $\rightarrow$ & UB & 0.567 & 0.524 & 0.108 & 4.86 & $* * *$ \\
\hline PS & $\rightarrow$ & UB & 0.092 & 0.090 & 0.069 & 1.307 & 0.191 \\
\hline $\mathrm{PC}$ & $\rightarrow$ & UB & 0.213 & 0.166 & 0.045 & 3.669 & $* * *$ \\
\hline UB & $\rightarrow$ & $\mathrm{OP}$ & 0.896 & 1.100 & 0.061 & 18.033 & $* * *$ \\
\hline PS & $\rightarrow$ & $\mathrm{PE}$ & 0.507 & 0.553 & 0.058 & 9.474 & $* * *$ \\
\hline PS & $\rightarrow$ & $\mathrm{PC}$ & 0.816 & 1.025 & 0.069 & 14.786 & $* * *$ \\
\hline
\end{tabular}

Note: ${ }^{*} p<0.05,{ }^{* *} p<0.01,{ }^{* * *} p<0.001$

Figure 2 Path analysis results

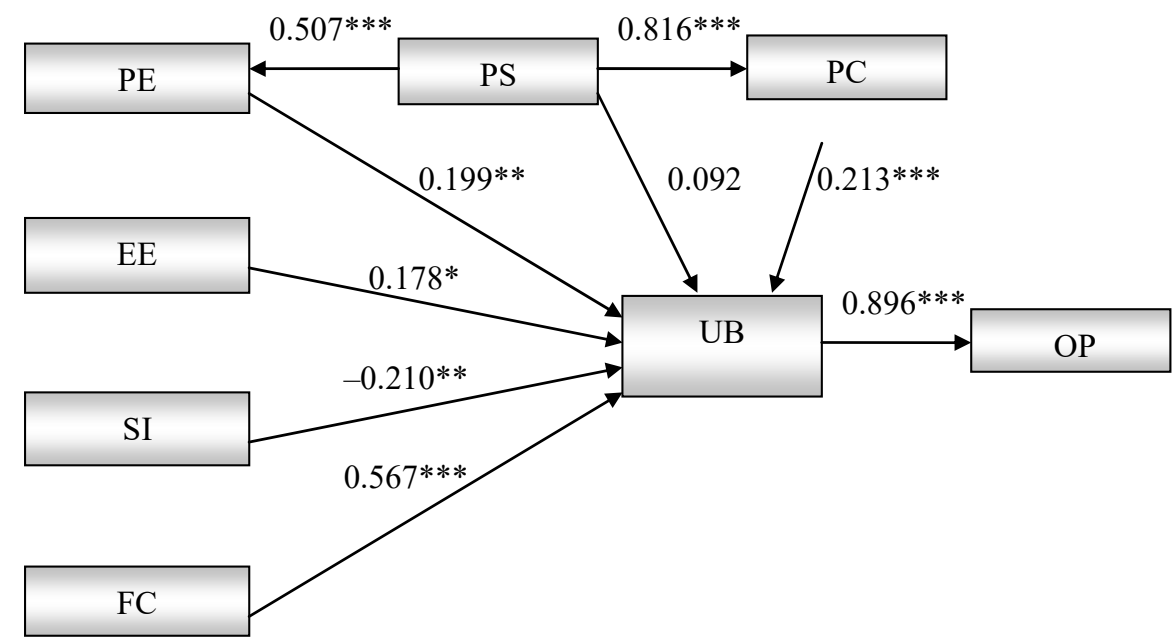

\subsection{Path analysis of the moderators}

Subsequently, this study investigated how participants' sex, age, and work experience moderated the effect of PE, EE, SI, and FC on their UB. The moderating effect of sex on UB attained an $R^{2}$ of 0.670 . Sex exerted a significant moderating effect on the relationships between $\mathrm{PE}$ and UB $(t=4.747, p=0.000)$, EE and UB $(t=3.356$, $p=0.001)$, and FC and UB $(t=9.387, p=0.000)$. Table 6 presents the path analysis results for the moderating effect of sex on UB. 
Table 6 Analysis results of the moderating effect of sex on UB

\begin{tabular}{|c|c|c|c|c|c|}
\hline & \multicolumn{2}{|c|}{ Non standardised coefficients } & \multirow{2}{*}{$\begin{array}{c}\begin{array}{c}\text { Standardised } \\
\text { coefficients }\end{array} \\
\text { Beta distribution }\end{array}$} & \multirow{2}{*}{$t$ value } & \multirow{2}{*}{ Sig. } \\
\hline & Estimates of $B$ & $S E$ & & & \\
\hline $\mathrm{PE}$ & 0.230 & 0.048 & 0.228 & 4.747 & $0.000 * * *$ \\
\hline $\mathrm{EE}$ & 0.186 & 0.056 & 0.175 & 3.356 & $0.001 * *$ \\
\hline SI & 0.080 & 0.047 & 0.077 & 1.707 & 0.089 \\
\hline $\mathrm{FC}$ & 0.437 & 0.047 & 0.447 & 9.387 & $0.000 * * *$ \\
\hline
\end{tabular}

Note: $* p<0.05, * * p<0.01, * * * p<0.001$

The moderating effect of age on UB attained an $R^{2}$ of 0.672 . Age exerted a significant moderating effect on the relationships between $\mathrm{PE}$ and UB $(t=4.673, p=0.000)$, EE and $\mathrm{UB}(t=3.430, p=0.001)$, and $\mathrm{FC}$ and $\mathrm{UB}(\mathrm{t}=9.518, p=0.000)$. Table 7 presents the path analysis results for the moderating effect of age on UB.

Table 7 Analysis results of the moderating effect of age on UB

\begin{tabular}{|c|c|c|c|c|c|}
\hline & \multicolumn{2}{|c|}{ Non standardised coefficients } & \multirow{2}{*}{$\begin{array}{c}\begin{array}{c}\text { Standardised } \\
\text { coefficients }\end{array} \\
\text { Beta distribution }\end{array}$} & \multirow{2}{*}{$t$ value } & \multirow{2}{*}{ Significance } \\
\hline & Estimates of $B$ & $S E$ & & & \\
\hline $\mathrm{PE}$ & 0.226 & 0.048 & 0.225 & 4.673 & $0.000 * * *$ \\
\hline $\mathrm{EE}$ & 0.190 & 0.055 & 0.178 & 3.430 & $0.001 * *$ \\
\hline SI & 0.065 & 0.047 & 0.063 & 1.383 & 0.167 \\
\hline $\mathrm{FC}$ & 0.443 & 0.047 & 0.454 & 9.518 & $0.000 * * *$ \\
\hline
\end{tabular}

Note: ${ }^{*} p<0.05, * * p<0.01, * * * p<0.001$

The moderating effect of work experience on UB attained an $R^{2}$ of 0.412 . Work experience had a significant moderating effect on the relationships between $\mathrm{PE}$ and UB $(t=4.819, p=0.000), \mathrm{EE}$ and $\mathrm{UB}(t=3.344, p=0.001)$, and $\mathrm{FC}$ and $\mathrm{UB}(t=9.370$, $p=0.000)$. Table 8 presents the path analysis results of the moderating effect of work experience on UB.

Table 8 Analysis results of the moderating effect of work experience on UB

\begin{tabular}{lccccccc}
\hline & \multicolumn{2}{c}{ Non standardised coefficients } & & \multicolumn{2}{c}{$\begin{array}{c}\text { Standardised } \\
\text { coefficients }\end{array}$} & \multirow{2}{*}{ t value } & Significance \\
\cline { 2 - 3 } & Estimates of $B$ & $S E$ & & Beta distribution & & \\
\hline PE & 0.233 & 0.048 & & 0.232 & 4.819 & $0.000^{* * * *}$ \\
EE & 0.186 & 0.056 & & 0.174 & 3.344 & $0.001^{* *}$ \\
SI & 0.075 & 0.047 & & 0.073 & 1.604 & 0.109 \\
FC & 0.439 & 0.047 & & 0.450 & 9.370 & $0.000^{* * *}$ \\
\hline
\end{tabular}

Note: $* p<0.05, * * p<0.01, * * * p<0.001$

After the moderators were added to the path analysis, the model indicated that sex, age, and work experience significantly moderated the effects of PE, EE, and FC on UB. Figure 3 shows the results of the path analysis with the moderators included. 
Figure 3 Path analysis results of moderators

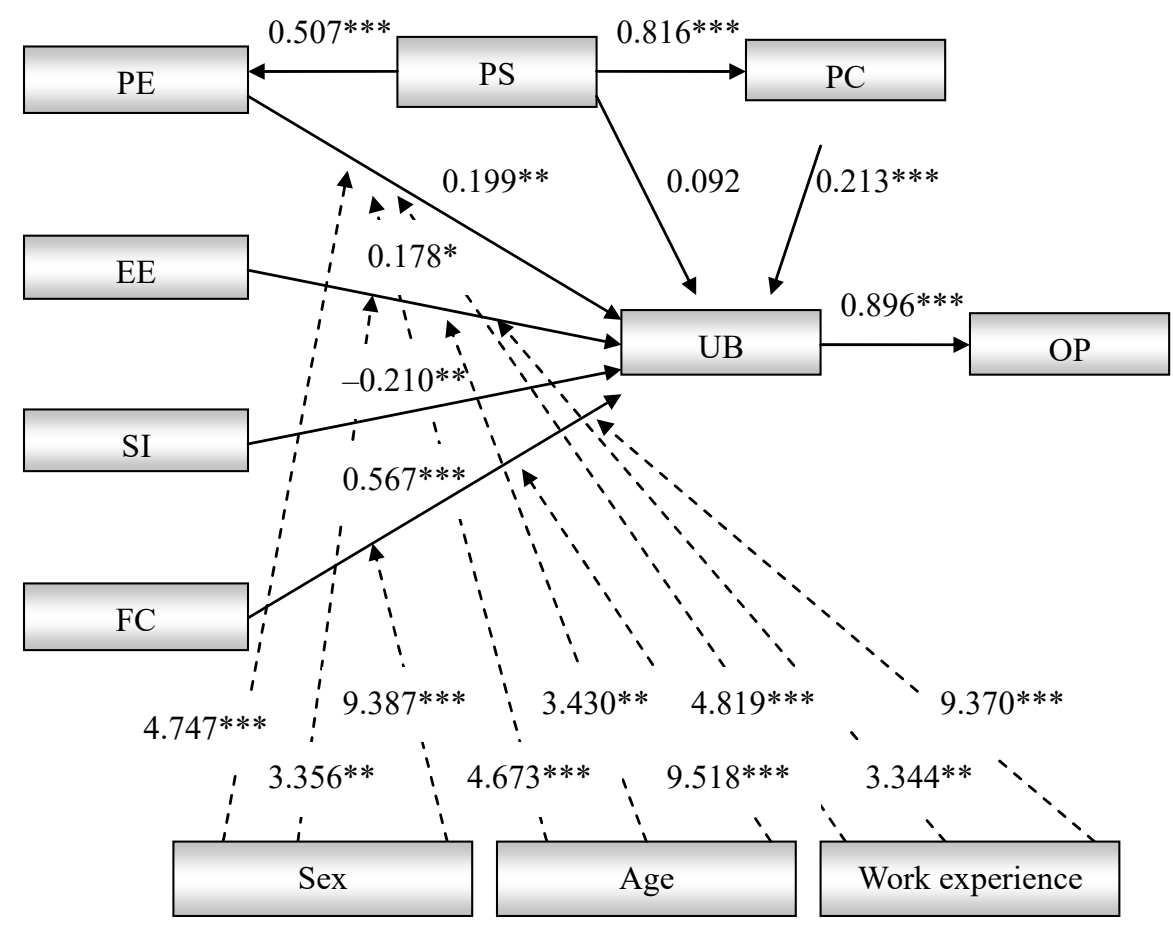

\section{Conclusions}

RFID has been widely applied in the healthcare industry for the tracking and management of medical equipment, health professionals, and patients in healthcare institutions among others. RFID applications cover people, assets, scheduling, and locations. Implementing RFID systems can enhance health professionals' work efficiency and patient safety, reduce working hours, and minimise risk. However, numerous healthcare institutions in Taiwan have not introduced or have only partially introduced RFID systems. Therefore, this study investigated health professionals' UB and OP after RFID systems were introduced at their healthcare institution. In addition to the development of digitised healthcare services, personal medical data have gradually been stored in digital formats, which have raised security and privacy issues. Therefore, in addition to discussing the introduction of RFID systems, this study also examined the effect of security and privacy on health professionals' UB.

The developed UTUAT model demonstrated that PE significantly and positively affects UB. RFID systems can indeed enhance health professionals' work efficiency and minimise human errors, thereby enhancing patient safety and the overall quality of healthcare services, eventually having a positive influence on UB. EE exerts a 
significantly positive influence on UB. With advancements in technology, RFID systems have become more convenient for use by health professionals. Manufacturers have shown increasing enthusiasm for developing RFID interfaces that are user-friendly. Consequently, health professionals' EE on RFID positively affects their UB. SI has a significantly negative effect on UB. RFID applications are becoming prevalent among healthcare institutions in Taiwan, and the internal policies of these healthcare institutions have further promoted RFID application use. The institutions promote RFID applications not only to satisfy hospital accreditation requirements, but also because they have been made aware of the benefits of RFID systems. FC exerts a significantly positive effect on UB. Along with the active implementation of RFID in healthcare institutions, numerous RFID usage-based training programs and courses have been provided. Numerous institutions make it mandatory that employees attend courses for a designated number of hours to ensure that they can use RFID systems properly. PS also has significantly positive influence on UB, indicating that in all the surveyed healthcare institutions, patient data are adequately controlled and monitored to ensure that health professionals recognise the importance of data protection in RFID systems.

In terms of the external derivatives of the UTUAT, PS significantly and positively affects $\mathrm{PE}$, indicating that increasing the trust that health professionals have in the security of RFID systems increases the frequency with which they use such systems, thereby enhancing their work efficiency. PS has a significantly positive effect on PC. When health professionals believe that an RFID system provides sufficient security for personal medical data, they are convinced that the personal privacy of their patients is properly protected, specifically that third parties will not be arbitrarily authorised to access and use protected data. UB has a significantly positive influence on OP. Because RFID systems substantially enhance health professionals' work efficiency, the number of errors made is reduced and the overall OP of healthcare institutions is increased. However, the effect of PS on UB was discovered to be insignificant, which was in contrast with the findings of a study by Hsu et al. (2013). This difference is likely attributable to the previous study investigating the effect of PS on intention to adopt rather than that on UB. Additionally, the present study inferred that because healthcare institutions implement strict control measures regarding medical data, numerous healthcare professionals must sign related nondisclosure agreements. Such stringent and complex control mechanisms may cause inconvenience to healthcare professionals; consequently, no positive effect is generated on health professionals' UB.

Regarding the data storage issue, Bessani et al. (2013) reported that most medical institutions have migrated their databases to cloud servers. While this can reduce costs, users who are accustomed to cloud-based storage must be made more aware of the security risks of such systems. Medical staff accustomed to storing patient data in the cloud is more likely to ignore the system's security features and pay less attention to their user behaviour.

Regarding the research framework's moderators of sex, age, and work experience, all hypotheses regarding the influence of $\mathrm{PE}, \mathrm{EE}$, and FC on UB were supported, demonstrating that healthcare professionals' different demographic variables moderate their UB of RFID systems in the UTUAT framework. The development of information technology and RFID systems in particular, has led to numerous innovations and breakthroughs in the healthcare industry. Increasing numbers of healthcare institutions have followed the trend and implemented their own RFID systems. This study demonstrated that introducing RFID systems to healthcare institutions substantially 
improves the healthcare services they provide. RFID systems not only increase health professionals' work efficiency but also reduce the frequency of medical errors. In time, RFID systems improve the overall quality of care provided by healthcare institutions, improve the institutions' OP, and raise their competitiveness.

Medical regulation restrictions may make it difficult in the future to obtain a lot of responses to healthcare questionnaires. Given sufficient budget and time, more questionnaires will thus be administered to improve these results in future studies. Other facets and adjustment variables will also be added in future research.

\section{References}

Alaiad, A. and Zhou, L. (2014) 'The determinants of home healthcare robots adoption: an empirical investigation', International Journal of Medical Informatics, Vol. 83, No. 11, pp.825-840.

Anderson, C.L. and Agarwal, R. (2011) 'The digitization of healthcare: boundary risks, emotion, and consumer willingness to disclose personal health information', Information Systems Research, Vol. 22, No. 3, pp.469-490.

Bansal, G., Zahedi, F. and Gefen, D. (2010) 'The impact of personal dispositions on information sensitivity, privacy concern and trust in disclosing health information online', Decision Support Systems, Vol. 49, No. 2, pp.138-150.

Bessani, A., Correia, M., Quaresma, B., Andre, F. and Sousa, P. (2013) 'DepSky: dependable and secure storage in a cloud-of-clouds', ACM Transactions on Storage, Vol. 9, No. 4, p.12.

Chang, Y-T., Syed-Abdul, S., Tsai, C-Y. and Li, Y-C. (2011) 'A novel method for inferring RFID tag reader recordings into clinical events', International Journal of Medical Informatics, Vol. 80, No. 12, pp.872-880.

Duyck, P., Pynoo, B., Devolder, P., Voet, T., Adang, L., Ovaere, D. and Vercruysse, J. (2010) 'Monitoring the PACS implementation process in large university hospital-discrepancies between radiologists and physicians', Journal of Digital Imaging, Vol. 23, No. 1, pp.73-80.

Fishbein, M. and Ajzen, I. (1975) Belief, Attitude, Intention and Behavior: An Introduction to Theory and Research, Addison-Wesley, Reading, MA.

Hadwich, K., Georgi, D., Tuzovic, S., Büttner, J. and Bruhn, M. (2010) 'Perceived quality of e-health services: a conceptual scale development of e-health service quality based on the C-OAR-SE approach', International Journal of Pharmaceutical and Healthcare Marketing, Vol. 4, No. 2, pp.112-136.

Han, S., Mustonen, P., Seppänen, M. and Kallio, M. (2006) 'Physicians' acceptance of mobile communication technology: an exploratory study', International Journal of Mobile Communications, Vol. 4, No. 2, pp.210-229.

Heselmans, A., Aertgeerts, B., Donceel, P., Geens, S., Van De Velde, S. and Ramaekers, D. (2012) 'Family physicians' perceptions and use of electronic clinical decision support during the first year of implementation', Journal of Medical Systems, Vol. 36, No. 6, pp.3677-3684.

Hsu, C-L., Lee, M-R. and Su, C-H. (2013) 'The role of privacy protection in healthcare information systems adoption', Journal of Medical Systems, Vol. 37, No.5, pp.1-12.

Jeng, D.J-F. and Tzeng, G-H. (2012) 'Social influence on the use of clinical decision support systems: revisiting the unified theory of acceptance and use of technology by the fuzzy DEMATEL technique', Computers and Industrial Engineering, Vol. 62, No. 3, pp.819-828.

Johnson, C.W. (2011) 'Identifying common problems in the acquisition and deployment of large-scale, safety-critical, software projects in the US and UK healthcare systems', Safety Science Vol. 49, No. 5, pp.735-745.

Katz, J.E. and Rice, R.E. (2009) 'Public views of mobile medical devices and services: a US national survey of consumer sentiments towards RFID healthcare technology', International Journal of Medical Informatics, Vol. 78, No. 2, pp.104-114. 
Kijsanayotin, B., Pannarunothai, S. and Speedie, S.M. (2009) 'Factors influencing health information technology adoption in Thailand's community health centers: applying the UTAUT model', International Journal of Medical Informatics, Vol. 78, No. 6, pp.404-416.

Kumar, S., Kadow, B.B. and Lamkin, M.K. (2011) 'Challenges with the introduction of radio-frequency identification systems into a manufacturer's supply chain - a pilot study', Enterprise Information Systems, Vol. 5, No. 2, pp.235-253.

Lai, H-M., Lin, I-C. and Tseng, L-T. (2014) 'High-level managers' considerations for RFID adoption in hospitals: an empirical study in Taiwan', Journal of Medical Systems Vol. 38, No. 2, pp.1-17.

Li, M., Lou, W. and Ren, K. (2010) 'Data security and privacy in wireless body area networks', IEEE Wireless Communications, Vol. 17, No. 1, pp.51-58.

Lin, J., Pai, J-Y. and Chen, C-C. (2012) 'Applied patent RFID systems for building reacting HEPA air ventilation system in hospital operation rooms', Journal of Medical Systems, Vol. 36, No. 6, pp.3399-3405.

Lu, M-T., Lin, S-W. and Tzeng, G-H. (2013) 'Improving RFID adoption in Taiwan's healthcare industry based on a DEMATEL technique with a hybrid MCDM model', Decision Support Systems, Vol. 56, No. 1, pp.259-269.

Maillet, É., Mathieu, L. and Sicotte, C. (2015) 'Modeling factors explaining the acceptance, actual use and satisfaction of nurses using an electronic patient record in acute care settings: an extension of the UTAUT', International Journal of Medical Informatics, Vol. 84, No. 1, pp.36-47.

Minvielle, E., Dervaux, B., Retbi, A., Aegerter, P., Boumendil, A., Jars-Guincestre, M.C., Tenaillon, A. and Guidet, B. (2005) 'Culture, organization, and management in intensive care: construction and validation of a multidimensional questionnaire', Journal of Critical Care, Vol. 20, No. 2, pp.126-138.

Nuq, P.A. and Aubert, B. (2013) 'Towards a better understanding of the intention to use e-health services by medical professionals: the case of developing countries', International Journal of Healthcare Management, Vol. 6, No. 4, pp.217-236.

Tate, E.B., Spruijt-Metz, D., O’Reilly, G., Jordan-Marsh, M., Gotsis, M., Pentz, M.A. and Dunton, G.F. (2013) 'mHealth approaches to child obesity prevention: successes, unique challenges, and next directions', Translational Behavioral Medicine, Vol. 3, No. 4, pp.406-415.

Tsai, Y. and Wu, S-W. (2010) 'The relationships between organisational citizenship behaviour, job satisfaction and turnover intention', Journal of Clinical Nursing, Vol. 19, Nos. 23-24, pp.3564-3574.

Venkatesh, V. and Davis, F.D. (1996) 'A model of the antecedents of perceived ease of use: development and test', Decision Sciences, Vol. 27, No. 3, pp.451-477.

Venkatesh, V., Morris, M.G., Davis, G.B. and Davis, F.D. (2003) 'User acceptance of information technology: toward a unified view', MIS Quarterly Management Information Systems, Vol. 27, No. 3, pp.425-478.

Wang, S-C., Lee, T-T., Liu, C-Y., Kao, C-H. and Kuo, M-C. (2015) 'A study on the acceptance by postpartum women of the RFID system applied during rooming-in care', Journal of Nursing and Healthcare Research, Vol. 11, No. 1, pp.74-83.

Zelbst, P.J., Green, K.W., Sower, V.E. and Reyes, P.M. (2012) 'Impact of RFID on manufacturing effectiveness and efficiency', International Journal of Operations and Production Management, Vol. 32, No. 3, pp.329-350. 